\title{
USO ATUAL DA TERRA NO MUNICÍPIO DE ILHA SOLTEIRA, SP, BRASIL: RISCOS AMBIENTAIS ASSOCIADOS
}

\section{CURRENT LAND USE IN ILHA SOLTEIRA, SÃO PAULO STATE, BRAZIL: ENVIRONMENTAL ASSOCIATED RISKS}

\section{Freitas-Lima, E. A. C. ${ }^{1}$, Silva, H.R. ${ }^{2}$; Altimare, A.L. ${ }^{3}$}

${ }^{1}$ Departamento de Biologia e Zootecnia, Faculdade de Engenharia de Ilha Solteira, UNESP, 15385-000, Ilha Solteira, São Paulo, Brasil.

${ }^{2}$ Departamento de Fitossanidade, Engenharia Rural e Solos, Faculdade de Engenharia de Ilha Solteira, UNESP

${ }^{3}$ Curso de Agronomia, Faculdade de Engenharia de Ilha Solteira, UNESP

\section{RESUMO}

Esse trabalho apresenta a utilização do sensoriamento remoto e do geoprocessamento na elaboração da Carta de Uso Atual da Terra no Município de Ilha Solteira, SP. Com base nessa carta foram identificados possíveis riscos ambientais para os ecossistemas aquáticos, associados aos usos atuais da terra. Discutiu-se ainda, o estado atual de degradação da paisagem, visando a definição de estratégias para a conservação ambiental.

Palavras-chaves: sistemas de informações geográficas, ecossistema aquático, riscos ambientais, planejamento da paisagem.

\section{ABSTRACT}

This paper presents the use of the Geographical Information System SPRING/INPE for mapping the current usage of the land in Ilha Solteira, SP, Brazil. This map was utilized as a base to determine the environmental risks resulting from antrophic activities to hydrography watershed components. It was also presented a discussion on the state of degradation 
of the landscape, with suggestions of options to the definition of strategies of environmental conservation.

Key words: geographical information systems, aquatic ecosystem, environmental risks, landscape planning.

\section{INTRODUÇÃO}

As atividades antrópicas produzem uma série de riscos e impactos para os componentes ambientais. A identificação e determinação geográfica dos possíveis riscos associados com as atividades antrópicas constitui-se num importante instrumento de análise ambiental, o qual pode ser utilizado para orientar programas de monitoramento ambiental. Por intermédio de uma carta de uso e ocupação da terra podem ser previstos os riscos ambientais associados com as atividades antrópicas.

A região de Ilha Solteira, no noroeste do Estado de São Paulo, apresenta uma grande importância em termos regionais, face à presença dos reservatórios das usinas hidrelétricas de Ilha Solteira, Jupiá e Três Irmãos. Ao mesmo tempo, a região concentra graves problemas ambientais, notadamente a erosão do solo e assoreamento destes reservatórios (SILVA e POLITANO, 1995; PAULA, 1997; BRANDINI, 2000), além da escassez de vegetação nativa (FREITAS-LIMA, 1997). Todos esses problemas foram resultantes da falta de planejamento ambiental, bem como do manejo inadequado dos recursos naturais.

A erosão hídrica do solo, associada com a falta de vegetação ciliar, está contribuindo para o assoreamento dos reservatórios de Ilha Solteira e Três Irmãos, portanto reduzindo a vida útil destas usinas hidrelétricas (SILVA e POLITANO, 1995). Andrade (2000) constatou que também a erosão eólica, atuando sobre os solos nas margens do reservatório de Três Irmãos, está propiciando a formação de dunas sobre áreas de pastagens, ou seja, está ocorrendo um grave processo de degradação ambiental: a desertificação.

Os dados obtidos por Gomide (1994), na análise dos custos ambientais decorrentes da implantação da Usina Hidrelétrica de Itaipu, podem mostrar os prejuízos decorrentes da erosão do solo para a vida útil das hidrelétricas. O reservatório desta usina vem recebendo um aporte de sedimentos, em suspensão e por arraste de fundo, da ordem de $47,34 \times 10^{6}$ t/ano, o que representa a descarga de uma caçamba de solos férteis de $6 \mathrm{~m}^{3}$ a cada segundo. 
Além do transporte de material particulado, associado com a erosão do solo, outros tipos de riscos ambientais para o componente água incluem o transporte de substâncias tóxicas, como pesticidas, e de agentes eutrofizantes (fertilizantes), os quais estão intimamente associados ao uso antrópico agro-pastoril, predominante na região. Neste contexto, bastante ilustrativa é a pesquisa de (GALO et al, 2002), em que os autores detectaram, por meio do sensoriamento remoto e geoprocessamento, extensas áreas ocupadas por macrófitas nos reservatórios das Usinas Hidrelétricas do Complexo Tietê, decorrente da carga de nutrientes que é despejada nestes corpos d'águas.

Considerando a situação da região de Ilha Solteira, com abundância de recursos hídricos e escassez de vegetação natural, é imprescindível a realização de um planejamento ambiental, visando alcançar uma maior proteção desses sistemas naturais. Nesse sentido, a elaboração de uma Carta de Uso Atual e Ocupação da Terra apresenta-se como um subsídio para um planejamento da paisagem do Município de Ilha Solteira, na tentativa de reverter o quadro regional de degradação de recursos naturais.

\section{MATERIAL E MÉTODOS}

\section{Área de estudo}

A área de estudo compreendeu o Município de Ilha Solteira (Figura 1), situado na Região Noroeste do Estado de São Paulo, Província Geomorfológica do Planalto Ocidental, região das "zonas indivisas", com relevo do tipo colinoso (SÃO PAULO, 1981). O embasamento geológico, suporte deste relevo, é representado principalmente pelas rochas sedimentares do Grupo Bauru, que ocorre em áreas que acompanham as cotas mais baixas dos vales dos rios afluentes do Paraná, e é constituída por arenitos de granulação de fina a média, dominantemente finos, pouca matriz e maciços cor vermelho escuro. A Formação Serra Geral, composta de basaltos também é encontrada, junto aos fundos de vale mais aprofundados. Nas planícies fluviais encontram-se os depósitos aluviais, areias e argilas, conglomerados na base (CEPAM, 1994).

Os solos presentes na área de estudo segundo (BRASIL, 1999) são os seguintes: LATOSSOLO VERMELHO Distrófico A moderado text. média rel. plano e suave ondulado (LV45), associação LATOSSOLO VERMELHO Eutroférrico e distroférrico + LATOSSOLO VERMELHO Distrófico ambos A moderado text. argilosa rel. suave ondulado (LV4), associação ARGISSOLO VERMELHO Eutrófico + ARGISSOLO VERMELHO - AMARELO Eutrófico ambos A moderado text. 
arenosa/média rel. suave ondulado (PV1), associação ARGISSOLO VERMELHO Eutrófico + ARGISSOLO VERMELHO-AMARELO Eutrófico ambos abrúpticos A moderado text. arenosa/média rel. suave ondulado e ondulado (PV2), associação NEOSSOLO QUARTZARÊNICO Órtico + LATOSSOLO VERMELHO text. média ambos Distróficos A moderado rel. plano e suave ondulado (RQ6).

A vegetação natural remanescente é composta pelas formações floresta latifoliada tropical, sendo também chamada de mata úmida e floresta latifoliada semi-decídua ou mata seca (SILVA, 1991).

\section{Procedimentos metodológicos}

A elaboração das cartas temáticas foi efetuada mediante a utilização do Sistema de Informações Geográficas SPRING/INPE versão 3.6.01 (INPE, 2002). Para a definição do projeto no SPRING adotou-se o meridiano central $51^{0} \mathrm{~W}$.

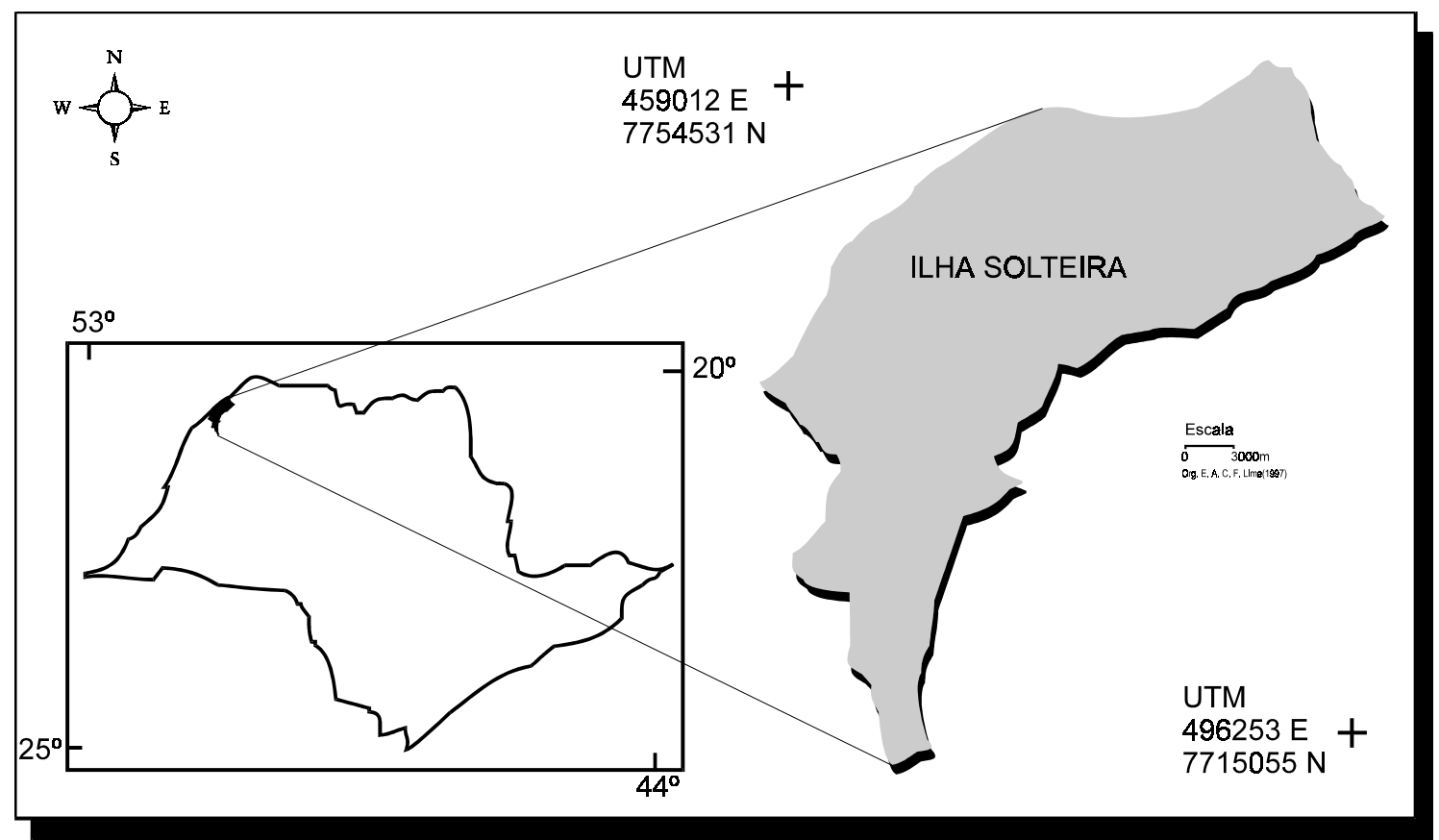

Figura 1 - Localização da área de estudo Fonte: Freitas-Lima, 1997).

Inicialmente a área de estudo foi dividida em Unidades de Gerenciamento - UGs, as quais corresponderam às áreas das bacias hidrográficas dos principais cursos d' água dentro do município. Os limites das bacias hidrográficas, bem como a rede hidrográfica, foram digitalizados em tela, com auxílio da ferramenta Edição Vetorial do Spring, utilizando-se um plano de informação elaborado com base nas cartas planialtimétricas, 
folhas Ilha Solteira (SF.22-C-II-3), Bela Floresta (SF.22-C-IV-1) e Esmeralda (SF.22-C-II-4), publicadas pelo Instituto Geográfico e Geológico de São Paulo - IGGSP em 1965, na escala 1:50000, (SÃO PAULO, 1965). A rede hidrográfica foi atualizada com informações obtidas da imagem de satélite, utilizada no presente trabalho.

Para a elaboração da Carta de Uso Atual e Ocupação da Terra foi conduzida a análise da imagem do satélite Landsat 7 ETM +, 3(R)4(G)5(B), órbita 222, ponto 74, datada de 12/08/2001. Como primeiro passo, efetuou-se o registro dessa imagem com a base topográfica, integrando-a ao Banco de Dados do SPRING. A seguir foi realizada a Transformação IHS da imagem visando realçar as bandas originais por meio de um aumento de contraste sobre a banda intensidade. Após essa operação, foi efetuada a fusão das bandas contrastadas com a banda PAN, para que a imagem resultante tivesse uma melhor resolução espacial.

A análise da imagem de satélite, após a Transformação IHS, foi efetuada de modo visual, digitalizando-se as classes temáticas na tela do monitor, com auxílio da ferramenta Edição Vetorial do SPRING, utilizando-se de características espectrais e dos elementos de reconhecimento, forma, textura e localização. Foram feitas observações em campo para verificação da verdade terrestre.

Com base nas classes temáticas digitalizadas foi realizado um mapeamento para modelo temático, o qual foi utilizado para a geração da Carta de Uso Atual e Ocupação da Terra, por intermédio do módulo Scarta do SPRING.

\section{RESULTADOS E DISCUSSÃO}

O Município de Ilha Solteira foi dividido em 9 Unidades de Gerenciamento (UGs), de modo a contribuir para com o processo de gestão ambiental local.

A utilização da bacia hidrográfica como unidade de gerenciamento baseou-se nos estudos de Odum (1988), Lima (1994) e Pires (1995), os quais ressaltam as interações entre os ecossistemas terrestres e aquáticos característicos desta unidade de paisagem.

A Tabela 1 apresenta algumas características das UGs identificadas, as quais encontram-se apresentadas na Figura 2. 
Tabela 1 - Áreas e principais cursos d'água das Unidades de Gerenciamento.

\begin{tabular}{|c|c|c|}
\hline UG & Área (ha) & Curso d'água principal \\
\hline UG1 & 3140,97 & $\begin{array}{c}\text { Córrego do Limoeiro - braço } \\
\text { atual da Represa de Ilha Solteira }\end{array}$ \\
\hline UG2 & 5988,81 & $\begin{array}{c}\text { Córrego Dezenove - braço atual } \\
\text { da Represa de Ilha Solteira }\end{array}$ \\
\hline UG3 & 14867,82 & $\begin{array}{c}\text { Córrego da Anta - braço atual da } \\
\text { Represa de Ilha Solteira }\end{array}$ \\
\hline UG4 & 15793,00 & $\begin{array}{c}\text { Rio São José dos Dourados - } \\
\text { braço atual da Represa de Ilha } \\
\text { Solteira }\end{array}$ \\
\hline UG5 & 2870,04 & $\begin{array}{r}\text { Córregos - Bairro Cinturão } \\
\text { Verde }\end{array}$ \\
\hline UG7 & 6288,09 & Córrego Caçula \\
\hline UG8 & 5332,16 & Córrego Pernilongo da Onça \\
\hline UG9 & 3102,37 & $\begin{array}{r}\text { Córregos Ponte Alta e Três } \\
\text { Irmãos }\end{array}$ \\
\hline
\end{tabular}




\section{Carta Hidrográfica do Município de Ilha Solteira - SP}

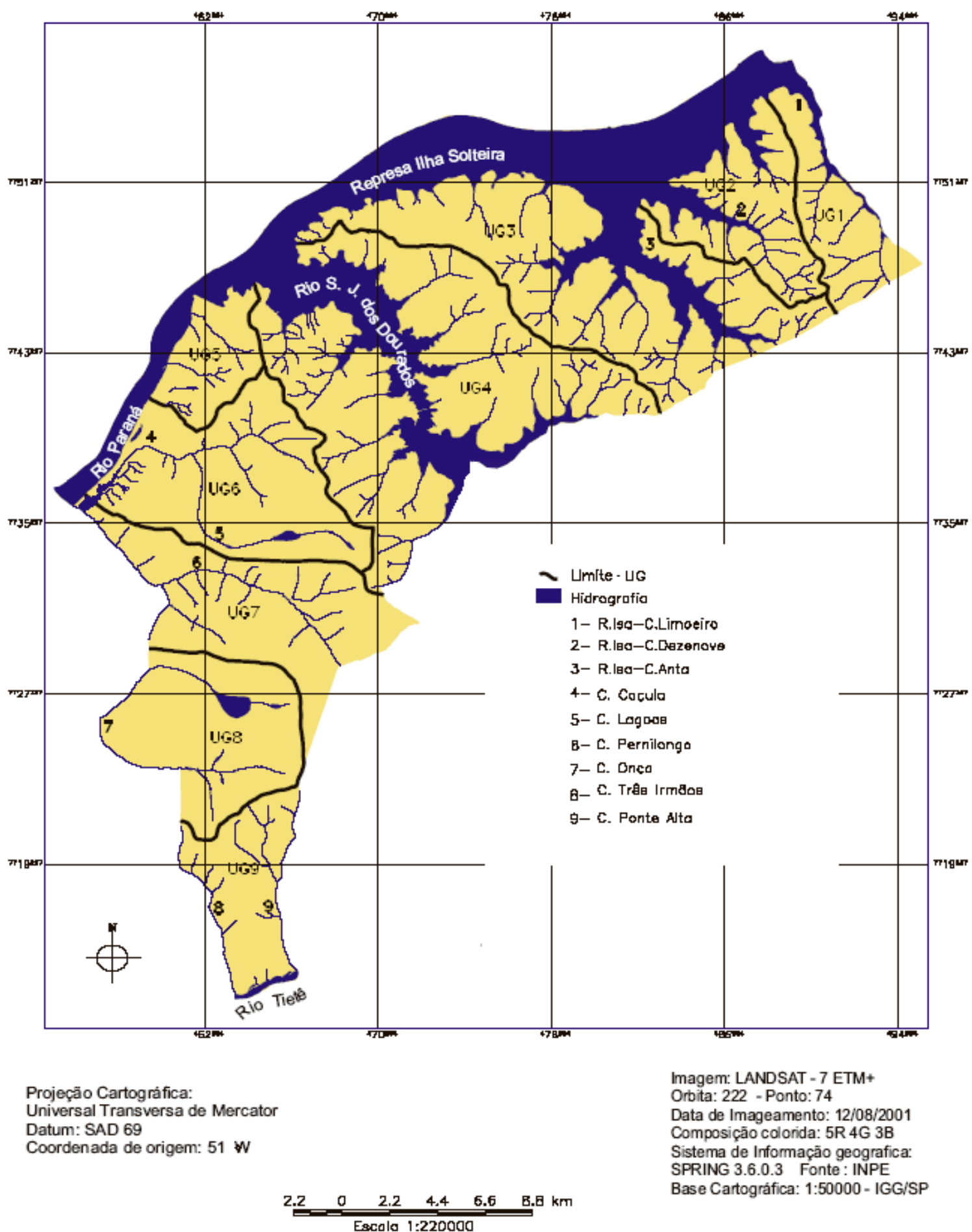

Figura 2 - Carta Hidrográfica do Município de Ilha Solteira. 
Como resultado da caracterização ambiental foi elaborada uma Carta de Uso Atual e Ocupação da Terra do Município de Ilha Solteira (Figura 3), em que podem ser identificadas as seguintes classes temáticas:

Fragmentos de mata: fragmentos remanescentes da vegetação original do município, representados pela floresta latifoliada tropical e floresta latifoliada semi-decídua (SILVA, 1991), em diversos estados de conservação. Foi também incluída nessa classe a vegetação de mata em estágios intermediários de sucessão ecológica, representada pela capoeira.

Vegetação ciliar: vegetação marginal aos sistemas aquáticos. Na maioria das vezes não se verificou a existência de uma mata ciliar, mas apenas vegetação herbácea e arbustiva, característica de estágios iniciais de sucessão ecológica em áreas anteriormente ocupadas por matas ciliares.

Pastagens: ecossistemas agrários voltados para a criação de gado, em diversos estados de degradação.

Culturas anuais: áreas com culturas de milho, feijão e soja, além, de solo nu, preparado para o cultivo.

Culturas perenes: áreas com culturas de banana, laranja e eucalipto.

Corpos d'agua: Rio Paraná, Rio Tietê, Represa de Ilha Solteira, represas localizadas na rede de drenagem do Município de Ilha Solteira

Área urbanizada: inclui o núcleo urbano original, construído pela CESP (Companhia Energética de São Paulo), além dos bairros Jardim Aeroporto e Jardim Novo Horizonte).

Áreas urbano-rurais: inclui os locais Cinturão Verde e Recanto das Águas constituídos por lotes de uso rural e de recreação, respectivamente, situados no perímetro urbano de Ilha Solteira, além do Bairro Ipê, constituído por chácaras e localizado no perímetro rural do município. 
Carta de Uso Atual e Ocupação da Terra - Iha Solteira - SP - 2003

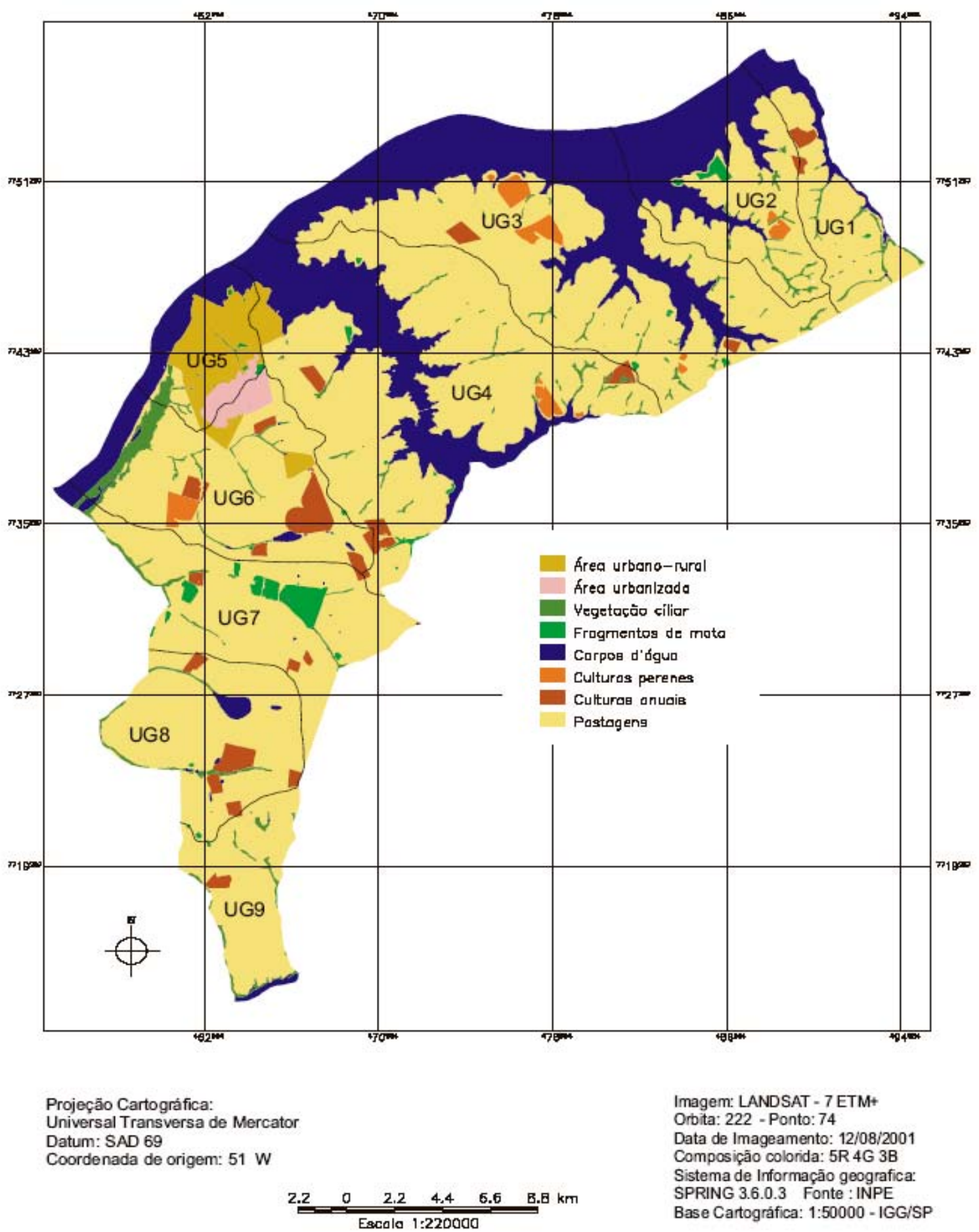

Figura 3 - Carta de Uso Atual e Ocupação da Terra do Município de Ilha Solteira. 
A análise da Tabela 2 demonstra que cerca de $74 \%$ da paisagem de Ilha Solteira apresenta-se ocupada por atividades antrópicas (urbanas e agrárias). Atualmente os remanescentes dos ecossistemas originais de mata aparecem como "manchas" numa paisagem em que a matriz é representada pelos agroecossistemas de pastagens.

Tabela 2: Usos da terra identificados no Município de Ilha Solteira.

\begin{tabular}{|c|c|c|}
\hline Usos da terra & Área $\left(\mathbf{K m}^{\mathbf{2}} \mathbf{)}\right.$ & Área (\%) \\
\hline Pastagens & 432,28 & 66,79 \\
\hline Culturas Anuais & 16,24 & 2,51 \\
\hline Culturas Perenes & 6,89 & 1,06 \\
\hline Fragmentos de Mata & 6,74 & 1,04 \\
\hline Vegetação Ciliar & 14,95 & 2,31 \\
\hline Área urbanizada & 5,71 & 0,88 \\
\hline Áreas urbano-rurais & 19,02 & 2,94 \\
\hline Corpos d'agua & 145,40 & 22,47 \\
\hline Total & 647,23 & 100 \\
\hline
\end{tabular}

Os sistemas naturais terrestres representam uma pequena porção da área do município, sendo representados pelos fragmentos remanescentes de mata (1\%) e pela vegetação ciliar (2\%). Na categoria vegetação ciliar estão incluídos vários estágios de desenvolvimento do ecossistema mata ciliar, desde suas formações iniciais, herbáceas, até aquelas arbustivas e arbóreas. Com a imagem de satélite utilizada, não foi possível a distinção nítida entre tais estágios. Por esse motivo, alguns fragmentos de matas ciliares podem ter sido incluídos na classe "vegetação ciliar".

A análise da história da ocupação da região, em que se situa Ilha Solteira, revela como foi o processo de transformação de uma área com cobertura predominante de mata para uma região, em que a paisagem predominante é representada por campos antrópicos e pastagens para gado (HESPANHOL, 1996).

De acordo com o levantamento dos principais usos da terra no Município de Ilha Solteira, as unidades de gerenciamento encontram-se em situações diferenciadas, em função dos riscos ambientais associados. $\mathrm{O}$ termo risco ambiental foi utilizado no presente estudo segundo o conceito adotado por Bordest (1992) e Pires (1995). O risco ambiental representa 
uma "possibilidade de degradação do componente (desestruturação, contaminação), sendo qualitativo e na maioria das vezes adimensional em termos de ocorrência e magnitude de impacto".

A Tabela 3 resume as relações entre os tipos de uso da terra (atividades antrópicas) e os possíveis riscos ambientais para os sistemas aquáticos.

A UG1 apresenta como uso predominante da terra, a pastagem. Apenas em alguns trechos do Córrego do Limoeiro, atualmente um braço da Represa de Ilha Solteira, observa-se vegetação ciliar. Portanto, o risco ambiental principal, para os sistemas aquáticos, nessa UG, refere-se à entrada de material particulado, com a conseqüente possibilidade de assoreamento, o que representa uma ameaça para a Represa de Ilha Solteira.

Tabela 3 - Uso atual da terra e riscos ambientais associados, considerando os sistemas aquáticos.

\begin{tabular}{|c|c|c|}
\hline Uso da terra & Risco ambiental & Efeitos Ambientais \\
\hline Pastagens & $\begin{array}{c}\text { Entrada de material particulado } \\
\text { e nutrientes }\end{array}$ & $\begin{array}{c}\text { Assoreamento. } \\
\text { Eutrofização. }\end{array}$ \\
\hline $\begin{array}{c}\text { Outras } \\
\text { Culturas }\end{array}$ & $\begin{array}{c}\text { Entrada de material particulado } \\
\text { e nutrientes; contaminação por } \\
\text { agrotóxicos }\end{array}$ & $\begin{array}{c}\text { Assoreamento. } \\
\text { Eutrofização. } \\
\text { Contaminação da biota. }\end{array}$ \\
\hline Urbanização & $\begin{array}{c}\text { Entrada de material } \\
\text { particulado, nutrientes, matéria } \\
\text { orgânica e substâncias tóxicas. }\end{array}$ & $\begin{array}{c}\text { Assoreamento. } \\
\text { Eutrofização. } \\
\text { Contaminação da biota. }\end{array}$ \\
\hline Estradas & $\begin{array}{c}\text { Entrada de material particulado } \\
\text { e de substâncias tóxicas. }\end{array}$ & $\begin{array}{c}\text { Assoreamento. } \\
\text { Contaminação da biota. }\end{array}$ \\
\hline
\end{tabular}

Fonte: Pires (1995, modificado)

As unidades de gerenciamento UG2, UG3 e UG4 encontram-se em situação semelhante, em termos de riscos ambientais, considerando-se o uso da terra predominante, pastagens. O manejo inadequado das pastagens, associado com a falta de proteção da vegetação marginal aos sistemas aquáticos, apresenta como conseqüência o risco de erosão do solo. Como conseqüência, uma vez mais, a Represa de Ilha Solteira está recebendo uma carga excessiva de material particulado. Vários trabalhos realizados abordam o problema do assoreamento de reservatórios em decorrência da erosão do solo do seu entorno (SILVA e POLITANO, 1995, PAULA, 1997; BRANDINI, 2000).

Os fragmentos remanescentes situados nessas unidades, tendo as pastagens como entorno, encontram-se sujeitos a riscos, principalmente de fogo, utilizado ainda como técnica de manejo. 
A UG4 apresenta uma porção caracterizada pelo uso urbano-rural, estando nela localizado o loteamento Recanto das Águas, às margens da Represa de Ilha Solteira (braço correspondente ao Rio S. J. dos Dourados). O atual depósito de resíduos sólidos do município (lixão) encontra-se situado sobre o divisor de águas, entre a UG4 e a UG5, próximo ao Rio S. J. dos Dourados (braço atual da Represa de Ilha Solteira), representando riscos de contaminação para água. Esse depósito será desativado e recuperado, uma vez que em breve deverá entrar em operação o novo aterro sanitário, localizado na UG7, segundo informações da Prefeitura Municipal de Ilha Solteira.

A UG6 apresenta uma porção urbana (Jardim Aeroporto), apesar de sua maior parte encontrar-se em área rural. Um dos canais que pertencem à bacia hidrográfica do Córrego Caçula, drena parte do loteamento urbano Jardim Aeroporto, apresenta processos erosivos avançados em suas margens.

O Bairro do Ipê, caracterizado por um uso urbano-rural (chácaras), localiza-se na UG6, abrigando uma das nascentes do Córrego do Ipê, afluente do Córrego Caçula (Figura 3). O Córrego das Lagoas é um dos afluentes do Córrego Caçula. Nas suas margens encontram-se cultivos agrícolas anuais, cujos principais riscos associados podem ser representados pela deriva de agrotóxicos.

A UG7 representa a unidade com maior porcentagem de cobertura vegetal, em termos de fragmentos remanescentes de mata. O Córrego do Pernilongo deságua no Córrego da Água Suja, o qual por sua vez, deságua no Rio Paraná. Próximo a um dos afluentes do Córrego da Água Suja encontra-se o local em que será instalado o novo aterro sanitário de Ilha Solteira, representando fonte de riscos ambientais de contaminação da água superficial e subterrânea.

O Córrego da Onça (UG 8) apresenta cultivos agrícolas anuais em seu canal principal e afluentes. As margens da represa conhecida como Lagoão, está totalmente desprovida de vegetação ciliar, com cultivos agrícolas marginais, representando risco ambiental associado com a contaminação por agroquímicos.

A UG 9 compreende a área das bacias hidrográficas que drenam para o Rio Tietê, na porção sul do município. Próximo à margem de um dos afluentes do Córrego Três Irmãos, que deságua no Rio Tietê, ocorre uma área de cultivo anual, com 57,70 ha, representando risco potencial de contaminação por agroquímicos para os sistemas aquáticos marginais (Figura 3).

Como resultado da caracterização ambiental efetuada pode-se indicar como unidades de gerenciamento prioritárias para um programa de monitoramento e recuperação ambiental, as unidades UG5, UG6 e UG7, 
nessa ordem. Os critérios utilizados na definição das prioridades compreenderam a existência de maiores riscos identificados (UG5 e UG6, respectivamente) e, melhor estado de conservação ambiental, representado pela maior proporção de fragmentos remanescentes de ecossistemas originais (UG7).

A UG5 apresenta uma prioridade maior, considerando sua característica de ocupação, ou seja, uma área de uso urbano e rural, com os riscos ambientais associados. A intervenção ambiental nesta UG deve incluir, em primeiro lugar, a elaboração de um plano diretor, como forma de ordenar a ocupação territorial. A recuperação das matas ciliares ao longo dos cursos d'água também é uma medida imprescindível. Um programa de monitoramento da qualidade da água dos ecossistemas aquáticos, desta UG, bem como um diagnóstico detalhado dos pontos de degradação ambiental deve ser desenvolvido.

A UG6, apesar de uso predominante rural, também apresenta uso urbano, portanto com riscos ambientais significativos. Além disso, essa é a UG com menor cobertura vegetal, em termos de fragmentos de mata. A intervenção ambiental nessa UG deve ser direcionada, principalmente, para a recuperação das matas ciliares ao longo dos córregos. Um programa de monitoramento da qualidade da água no Córrego Caçula deveria ser implantado.

A UG7 deve receber prioridade nos programas ambientais municipais pela conjunção dos fatores maior cobertura vegetal natural, que deve ser preservada, e a presença do aterro sanitário de resíduos sólidos urbanos. Um programa de monitoramento da qualidade da água no Córrego da Água Suja é de extrema necessidade.

Além das ações indicadas para as UG prioritárias, algumas outras sugestões para um programa ambiental municipal, tendo em vista a análise do uso atual e ocupação das terras do Município, incluem:

1. Programa de Zoneamento Ecológico e Econômico (ZEE) do Município. Com este instrumento de gestão ambiental, o poder público pode prever ações que direcionem o desenvolvimento, considerando as potencialidades e limitações ecológicas e econômicas do seu território.

2. Organização de um Sistema de Informações Ambientais com acesso público.

3. Plano Diretor de Desenvolvimento Municipal.

4. Programa de recomposição de matas ciliares marginais aos córregos e represas (principalmente a Represa de Ilha Solteira), de áreas de Reserva Legal e proteção de fragmentos remanescentes de mata como unidades de conservação ambiental.

5. Programa de educação ambiental direcionado à comunidade rural e urbana. 


\section{CONCLUSÕES}

A localização espacial das atividades antrópicas, por intermédio de uma Carta de Uso Atual e Ocupação das Terras, constitui-se numa eficiente ferramenta de análise ambiental, dotando os tomadores de decisão de informações necessárias para atuação no escopo da gestão ambiental. Estando as informações organizadas na forma de banco de dados, dentro de um Sistema de Informações Geográficas, como o SPRING, sua consulta é mais ágil, assim como também, a solução dos problemas ambientais detectados.

\section{REFERÊNCIAS}

ANDRADE, F.B. Estudo para identificação da origem de erosões marginais no Reservatório da UHE de Três Irmãos. Três Irmãos, 51p., 2000.(Trabalho de graduação apresentado à Faculdade de Geografia, Universidade Federal do Mato Grosso do Sul, Campus de Três Lagoas, para a obtenção do título de geógrafo).

BORDEST, S. M. L. Riscos ambientaisna Alta Bacia do Coxipó - MT.

UNESP, Rio Claro, SP, 1992. (Tese de Doutorado).

BRANDINI, O.L. Tipologia e distribuição dos processos erosivos do Município de Suzanápolis, SP. Três Lagoas, 40p., 2000. (Trabalho de graduação apresentado à Faculdade de Geografia, Universidade Federal do Mato Grosso do Sul, Campus de Três Lagoas, para a obtenção do título de Geógrafo).

BRASIL. Empresa Brasileira de Pesquisas Agropecuárias: Mapa pedológico do Estado de São Paulo. Mapa 13-Urubupungá, color, 100 $\mathrm{cmx} 70 \mathrm{~cm}$. Escala 1:500000. (legenda expandida). Campinas: Engemap, 1999.

CENTURION, J.F. Balanço Hídrico da Região de Ilha Solteira. Científica, Jaboticabal, v.10, n.1, p.57-61, 1982.

CEPAM - CENTRO DE ESTUDOS E PESQUISAS DE ADMINISTRAÇÃO MUNICIPAL. Plano de desenvolvimento integrado e legislação de uso e ocupação solo dos municípios da área lindeira aos rios Tietê - Paraná do Estado de São Paulo - Sub-região 2. São Paulo, CEPAM, 1994.

FREITAS LIMA,E. A C. Estudo da paisagem do Municipio de Ilha Solteira-SP: subsídios para o planejamento fisico ambiental. São Carlos, UFSCar, 120p., 1997. (Tese de doutorado). 
GALO, M. L. B. T. et al. Uso do sensoriamento remoto orbital no monitoramento da dispersão de macrófitas nos Reservatórios do Complexo Tietê. Planta Daninha. v. 20, 7-20p., 2002.

GOMIDE, F.L.S. Recuperação de áreas degradadas: a visão do dirigente. In: SIMPÓSIO NACIONAL RECUPERAÇÃO DE ÁREAS DEGRADADAS, 2, 1994, Curitiba. Anais... Curitiba: FUPEF, 9398p.,1994.

HESPANHOL, A. N. Dinâmica agroindustrial, intervenção estatal e a questão do desenvolvimento da Região de Andradina - SP. Instituo de Geociências e Ciências Exatas, Rio Claro, SP, UNESP. 273p., 1996. (Tese de doutorado).

INSTITUTO NACIONAL DE PESQUISAS ESPACIAIS Spring, versão 3.6.01. INPE, 2002. CD-ROM.

LIMA, M. A. Avaliação da qualidade ambiental de uma microbacia no Município de Rio Claro - SP. Rio Claro, UNESP, 1994. 264p. (Tese de Doutorado).

ODUM, E. P. Ecologia. Rio de Janeiro. Interciências.434p., 1988.

PAULA, R.C. Avaliação dos principais fatores do meio físico do Município de Suzanápolis, S.P., relacionados com a produção agropecuária mediante o emprego de imagens aéreas. Ilha Solteira: UNESP, 1997. 47p. (Trabalho de graduação apresentado à Faculdade de Engenharia de Ilha Solteira, Universidade Estadual Paulista, Campus de Ilha Solteira, para a obtenção do título de Engenheira Agrônoma).

PIRES, J. S. R. Análise ambiental voltada ao planejamento $e$ gerenciamento do ambiente rural: abordagem metodológica aplicada ao Município de Luiz Antônio - SP. São Carlos, UFScar, 1995. 194p. (Tese de Doutorado).

SÃO PAULO (Estado). Instituto Geográfico e Cartográfico do Estado de São Paulo. Carta Topográfica. Folhas SF-22-C-II-3; SF-22-C-II-4M; $S F-22-C-I V-1$. Escala: 1:50000. São Paulo: IGGSP, 1965.

SÃO PAULO. Secretaria da Indústria, Comércio, Ciência e Tecnologia. Instituto de Pesquisa Tecnológicas do Estado de São Paulo- IPT. Mapa Geomorfológico do Estado de São Paulo. São Paulo: IPT, v. 1, 1981. (Boletim Técnico de Ciências, 1).

SILVA et al. Proposta metodológica para a elaboração de zoneamento agrícola nos municípios do Noroeste Paulista. In: SIMPÓSIO BRASILEIRO DE SENSORIAMENTO REMOTO, 8, 1996, Salvador. Anais... Salvador: INPE, 1996.

SILVA, H. R. Avaliação dos principais fatores do meio físico do Município de Pereira Barreto, SP, relacionados com a produção agropecuária,mediante o emprego de imagens aéreas. Ilha Solteira, UNESP/FEIS, 1991. (Relatório do plano trienal de pesquisa). 
SILVA.H.R; POLITANO, W. Análise do uso e ocupação do solo e processos de erosão na área de influência do conjunto de Urubupungá: Estudo dos municípios de Pereira Barreto, Ilha Solteira e Suzanápolis (SP). In: SIMPÓSIO NACIONAL DE CONTROLE DE EROSÃO, 5, Bauru-SP, 1995. Anais...Bauru: ABGE-IPT-DIGEO, 1995.p.14547.ABGE-IPT-DIGEO. 